\title{
CORRIGENDUM
}

\section{Effect of a nutrient-enriched drink on dietary intake and nutritional status in institutionalised elderly}

\author{
M Manders, CPGM de Groot, YH Blauw, RAM Dhonukshe-Rutten, L van Hoeckel-Prüst, JG Bindels, \\ E Siebelink and WA van Staveren
}

European Journal of Clinical Nutrition (2009) 63, 1276; doi:10.1038/ejcn.2009.52

Correction to: European Journal of Clinical Nutrition (2009) 63, 1241-1250; doi:10.1038/ejcn.2009.28; published online 20 May 2009

Since the online publication of this article on 20 May 2009, the authors have identified an error in Table 3 . The column heading Placebo group $(n=30)$ should be Placebo group $(n=13)$. The correct table is shown below.

The authors apologize for any inconvenience caused.

Table 3 Effect of 24 weeks nutritional intervention on dietary intake in Dutch institutionalised elderly people

\begin{tabular}{|c|c|c|c|c|c|c|c|}
\hline \multirow[t]{2}{*}{ Variable } & \multicolumn{3}{|c|}{ Supplement group $(\mathrm{n}=30)$} & \multicolumn{3}{|c|}{ Placebo group $(\mathrm{n}=13)$} & \multirow[t]{2}{*}{ P-value } \\
\hline & Week 0 & Week 24 & Change & Week 0 & Week 24 & Change & \\
\hline $\begin{array}{c}\text { Energy intake (MJ/day) } \\
<\text { Reference, } \%\end{array}$ & $\begin{array}{c}7.17 \pm 1.83 \\
30\end{array}$ & $\begin{array}{l}7.58 \pm 1.57 \\
15\end{array}$ & $0.23 \pm 1.83$ & $\begin{array}{c}7.15 \pm 1.39 \\
38\end{array}$ & $\begin{array}{c}6.59 \pm 1.71 \\
38\end{array}$ & $-0.56 \pm 1.60$ & 0.193 \\
\hline $\begin{array}{l}\text { Protein (g/day) } \\
\quad<\text { Reference, \% }\end{array}$ & $\begin{array}{c}59.9 \pm 15.5 \\
6\end{array}$ & $\begin{array}{c}67.5 \pm 14.6 \\
4\end{array}$ & $6.3 \pm 14.7$ & $\begin{array}{c}58.8 \pm 15.4 \\
8\end{array}$ & $\begin{array}{c}56.7 \pm 13.3 \\
8\end{array}$ & $-2.1 \pm 11.8$ & 0.079 \\
\hline Fat (g/day) & $61.4 \pm 19.7$ & $68.1 \pm 17.6$ & $4.6 \pm 19.8$ & $60.2 \pm 18.8$ & $58.0 \pm 18.3$ & $-2.2 \pm 22.4$ & 0.338 \\
\hline Carbohydrate (g/day) & $213.4 \pm 56.3$ & $219.1 \pm 48.3$ & $1.0 \pm 62.0$ & $223.8 \pm 38.8$ & $199.5 \pm 55.7$ & $-24.3 \pm 39.2$ & 0.186 \\
\hline Dietary fibre (g/day) & $16.3 \pm 5.9$ & $18.2 \pm 4.4$ & $1.4 \pm 6.5$ & $14.8 \pm 2.4$ & $12.9 \pm 5.1$ & $-1.9 \pm 4.5$ & 0.108 \\
\hline $\begin{array}{l}\text { Calcium (mg/day) } \\
<\text { Reference, } \%\end{array}$ & $\begin{array}{c}840.5 \pm 306.4 \\
50\end{array}$ & $\begin{array}{c}1114.2 \pm 322.2 \\
19\end{array}$ & $262.5 \pm 253.7$ & $\begin{array}{c}896.6 \pm 281.4 \\
38\end{array}$ & $\begin{array}{c}862.1 \pm 214.7 \\
46\end{array}$ & $-34.5 \pm 213.4$ & 0.001 \\
\hline $\begin{array}{l}\text { Vitamin A RE (mg/day) } \\
\quad<\text { Reference, } \%\end{array}$ & $\begin{array}{c}0.7 \pm 0.8 \\
53\end{array}$ & $\begin{array}{l}1.1 \pm 0.9 \\
30\end{array}$ & $0.4 \pm 1.2$ & $\begin{array}{l}0.5 \pm 0.2 \\
69\end{array}$ & $\begin{array}{c}0.7 \pm 0.4 \\
54\end{array}$ & $0.2 \pm 0.4$ & 0.513 \\
\hline $\begin{array}{l}\text { Thiamine (mg/day) } \\
\text { < Reference, \% }\end{array}$ & $\begin{array}{c}0.7 \pm 0.2 \\
57\end{array}$ & $\begin{array}{l}2.2 \pm 0.6 \\
4\end{array}$ & $1.5 \pm 0.6$ & $\begin{array}{c}0.7 \pm 0.2 \\
62\end{array}$ & $\begin{array}{c}0.6 \pm 0.2 \\
69\end{array}$ & $-0.1 \pm 0.2$ & $<0.001$ \\
\hline $\begin{array}{l}\text { Riboflavin (mg/day) } \\
\quad<\text { Reference, \% }\end{array}$ & $\begin{array}{c}1.2 \pm 0.4 \\
13\end{array}$ & $\begin{array}{c}2.7 \pm 0.7 \\
0\end{array}$ & $1.5 \pm 0.6$ & $\begin{array}{c}1.3 \pm 0.4 \\
15\end{array}$ & $\begin{array}{c}1.2 \pm 0.3 \\
8\end{array}$ & $-0.1 \pm 0.2$ & $<0.001$ \\
\hline $\begin{array}{l}\text { Vitamin } \mathrm{B}_{6} \text { (mg/day) } \\
\quad<\text { Reference, } \%\end{array}$ & $\begin{array}{c}1.0 \pm 0.2 \\
60\end{array}$ & $\begin{array}{c}2.9 \pm 0.6 \\
4\end{array}$ & $1.9 \pm 0.7$ & $\begin{array}{c}0.9 \pm 0.2 \\
62\end{array}$ & $\begin{array}{c}0.8 \pm 0.3 \\
77\end{array}$ & $-0.1 \pm 0.2$ & $<0.001$ \\
\hline $\begin{array}{l}\text { Folate }(\mu \mathrm{g} / \text { day }) \\
\quad<\text { Reference, } \%\end{array}$ & $\begin{array}{c}180.1 \pm 63.1 \\
63\end{array}$ & $\begin{array}{c}490.5 \pm 109.8 \\
4\end{array}$ & $306.1 \pm 120.5$ & $\begin{array}{c}170.1 \pm 44.2 \\
69\end{array}$ & $\begin{array}{c}168.8 \pm 35.3 \\
77\end{array}$ & $-1.3 \pm 35.6$ & $<0.001$ \\
\hline $\begin{array}{l}\text { Vitamin } B_{12}(\mu \mathrm{g} / \text { day }) \\
\quad<\text { Reference, } \%\end{array}$ & $\begin{array}{c}3.2 \pm 1.4 \\
17\end{array}$ & $\begin{array}{c}6.1 \pm 2.2 \\
4\end{array}$ & $2.8 \pm 2.2$ & $\begin{array}{c}2.8 \pm 1.1 \\
23\end{array}$ & $\begin{array}{c}2.6 \pm 1.1 \\
23\end{array}$ & $-0.2 \pm 0.8$ & $<0.001$ \\
\hline $\begin{array}{l}\text { Vitamin C (mg/day) } \\
\quad<\text { Reference, \% }\end{array}$ & $\begin{array}{c}50.1 \pm 31.4 \\
47\end{array}$ & $\begin{array}{c}221.0 \pm 64.6 \\
4\end{array}$ & $169.3 \pm 67.9$ & $\begin{array}{c}63.7 \pm 43.7 \\
38\end{array}$ & $\begin{array}{c}50.8 \pm 41.2 \\
62\end{array}$ & $-12.9 \pm 49.6$ & $<0.001$ \\
\hline $\begin{array}{l}\text { Vitamin D ( } \mu \mathrm{g} / \text { day) } \\
\quad<\text { Reference, } \%\end{array}$ & $\begin{array}{c}3.4 \pm 1.8 \\
100\end{array}$ & $\begin{array}{c}11.3 \pm 3.3 \\
33\end{array}$ & $7.8 \pm 3.5$ & $\begin{array}{c}2.7 \pm 1.0 \\
100\end{array}$ & $\begin{array}{c}2.7 \pm 1.0 \\
100\end{array}$ & $0.0 \pm 0.8$ & $<0.001$ \\
\hline $\begin{array}{l}\text { Vitamin E (mg/day) } \\
\quad<\text { Reference, } \%\end{array}$ & $\begin{array}{c}9.9 \pm 4.2 \\
10\end{array}$ & $\begin{array}{c}52.4 \pm 14.8 \\
0\end{array}$ & $42.2 \pm 14.5$ & $\begin{array}{c}9.7 \pm 3.9 \\
0\end{array}$ & $\begin{array}{c}7.4 \pm 3.2 \\
38\end{array}$ & $-2.3 \pm 4.6$ & $<0.001$ \\
\hline
\end{tabular}

Data shown as mean \pm s.d.

${ }^{a}$ Differences between changes during 24 weeks in supplement group and placebo group. Reference value for vitamins and minerals is two-thirds of the Dutch RDA (Health Council of the Netherlands, 2000, 2001, 2003); energy: \% below 6.3 MJ/day (de-Groot et al., 1996). 